\title{
An Acquisition Support System for Public Healthcare - Case Study of the U.S. Children Vaccine Program
}

\author{
H.B. Wang, W. Wang \\ Texas A\&M International University \\ Laredo, Texas USA
}

Da Huo

Central University of Finance and Economics Beijing, China

\author{
Jaime Oritz \\ University of Houston \\ Houston, Texas US \\ Y.Q. Xu \\ Georgia Gwinnett College \\ Lawrenceville, GA USA
}

\begin{abstract}
This study aims to analyze the existing federal acquisition policy in public healthcare in the United States, especially in the case of childhood immunization, and then propose a new multiple items multiple vendors model to accomodate these criteria, with the objectives of lowering costs including transportation and wastage. It develops an integrated spreadsheet based software to collect data with an automated web based scraper/crawler that allows to: forecast demand, analyze vendors, estimate overall cost and provide useful information for decision makers. This study uses the case of children's immunization vaccines as an example to illustrate its contribution. . The proposed system also addresses the challenge of implementing the new government recommended immunization requirements in a cost effective manner. In addition, the new acquisition decision support system enhances the transparency of healthcare costs, especially in the public health service.
\end{abstract}

Keywords-decision support; multiple criteria; transportation; public healthcare

\section{INTRODUCTION}

The shortage of the influenza A virus (H1N1) vaccine in 2009 and other similar incidents in the past ten years[1, 2], including shortages in children's immunization vaccines, is what motivates the authors of this study to investigate the existing acquisition policy in the healthcare industry. The frequent was tagein vaccine[3] and other emergency medical supplies cost taxpayers billions of dollars each year due to a poorly managed acquisition policy by the healthcare industry[4]. This wastage adds to the high cost of healthcare in the United States, which is higher comparing to other developed countries[5]. One major area where vaccine wastage occurs is during childhood immunizations, which is conpounded by the challenge of incorporating new vaccines into the already crowded immunization schedule adopted by the U.S. governement. In addition, an increasing numbers of health providers and parents are opposed to add immunization requirements, which prevents an efficient resource management[6-8].

One approach to reduce wastage and overall costs in the healthcare industry is to develop better acquisition policy tools than are currently available to decision makers. According to the Centers for Disease Control and Prevention (CDC), there are a number of manufacturers who can provide multiple vaccines and other emergency supplies with different pricing schedules, even under the Federal contract purchase price due to different purchase financing systems[9-12]. These manufacturers can also offer different pricing schedules on the purchase of combinations of vaccines to enable purchasers to take advantage of the economies of scale[13]. However, these manufacturers are privately owned and profit driven organizations, and their production schedule depends on the nature of vaccine production and on accurately predicting the market needs. These needs include purchase contracts from the Federal government, public sector and private clinics, which result in manufacturers having little motivation to provide pricing flexibility $[14,15]$. These challenging issues are here investigated and a new acquisition model is proposed to lower costs and reduce wastage.

\section{PRIOR POLICY ANALYSES AND RESEARCH STUDIES}

According to a 2006 study by [16], none of the existing decision support systems which handle contract types and organization relationships consider quality management because its complexity, although the U.S. Department of Defense began employing quality management techniques after the WWII[7, 17, 18]. Other government agencies such as NASA also employ a quality assurance standard to their contractors[19]. Quality management concepts have also been examined in the context of the public health care field[20,21]. In the private sector, a quality management decision support system is implemented as a part of the Enterprise Resource Planning System as a tool to collect data from different suppliers. Academic researchers in the quality management fields study the impact of information on contracting and quality management and some recommend the structure of a decision support system as a concept and define a prototype but never implemented it as operational tools that can be easily used/integrated into existing procurement systems. Their proposed mathematical models focus on finding the key factors by using analytic hierarchy processes for multiple criteria under the assumption of independency of criteria. There is no quantitative analysis tool available to a decision-maker in the acquisition process to evaluate/select vendors. Many existing decision support systems in the acquisition process are document based to provide guidelines/information, for example, 
the Surface Decision Support System provided to the U.S. Department of Transportation.

According to the General Service Administration and the U.S. Department of Health and Human Service, the existing acquisition policies and procedures conform to the Federal Acquisition Regulation System (FARS), which monitors contracting relationships between the contracting offices and contractors. A quality surveillance plan should be implemented and the contractor should be evaluated on performance based criteria. There are 11 criteria to be considered but the evaluation is carried out by an expert panel with a list of weighted factors to be considered. There is no general decision support system available to the decision maker (expert panel) on evaluating the vendors based on the quality management criteria in addition to the criteria listed by the FARS. . These criteria are weighted according to the general guideline but no specific model or tool is available to integrate the criteria into a software system for decision support. The FARS and its related policies might bring challenges in adopting this decision support system software across federal agencies. One of the main challenges will be the organizational resistance to adopt a new decision tool and the difficulty of integrating that tool into the different systems each agency uses. However, there is no barrier in the private sector for adopting the proposed system as an analytical tool to help businesses improve their performance. Contractors can also employ the tool to design financial strategies to customize service packages, or to better estimate the cost of transportation. If the decision support system becomes popular among the contractors, it will increase its credibility among federal agencies and encourage the effort to integrate it into their decision support systems.By designing this new tool in a spreadsheet based format, this should reduce implementation barriers, as it can be easily integrated into existing procurement systems.

\section{Methodology}

This study departs from current acquisition practices and brings significant innovation to the acquisition model. Its main advantages and innovations are: 1) automatic data collecting from different sources and forecasting of demands; 2) a new two-step decision model with the evaluation procedure of suppliers on quality management criteria, via a data envelopment analysis (DEA) approach, and the selection procedure of suppliers on supplier interdependent criteria, via a non-linear multiple criteria decision analysis (MCDA) approach; 3) address multiple issues simultaneously in the model; 4) an integrated spreadsheet based software system that includes the cost of distribution and transportation, and is designed to be easily to implemented with current medical management systems in public and private sectors.

The model and methods are programmed into a speadsheet based software system. The real world data such as the federal contracted companies and other medical suppliers from the CDC website and other public domains will be collected using web based free screen scraper or crawler software and used to evaluate the performance of the proposed model. The outcomes of the proposal model and methodology are measured through a simulation using real world data with different scenarios in terms of acquisition cost, quality management of different vendors, and other criteria.

The first stage of the research is to analyze the data collected and stored in a spreadsheet format by the web based automatic scraper/crawler from the CDC websites, U.S. Census, the U.S. Department of Health and Human Services, General Service Administration, and other public domains. The development of the demand forecast involves several statistical methods (available on the spreadsheet software) such as multiple regression analysis, nonlinear regression, decomposition analysis, adaptive filtering, and trend analysis. The forecasting error is analyzed through the analysis of variance.

The second stage is to build a decision model for acquisition, which consists of two steps: 1) evaluation and selection; and 2) cost optimization. The evaluation process of multiple suppliers is based on an extension of the data envelopment analysis (DEA) model using quality management criteria in addition to the criteria listed in the Federal Acquisition Regulation for the public sector and reports the rank of the suppliers of each product to create a preferred supplier pool. In the private sector, the criteria listed in the FARS will be considered as optional criteria. The selection process of multiple suppliers is a nonlinear multi criteria decision analysis (MCDA) model based on the analysis of the interdependence among products and suppliers from the pool of preferred suppliers and it reports the best groups of suppliers. The transportation cost optimization is based on the fixedcharge transportation model.

The quality management based DEA model provides a rounded judgment on supplier performance taking into consideration multiple quality management criteria simultaneously, including the criteria listed in the FARS and then combining them into a single measure for quality control. The mathematical model is solved for every medical item and the relative quality score of each supplier is determined. The results of the DEA model show that the higher a supplier's quality score in relation to the corresponding score of another supplier, the higher the rank of this supplier is in term of quality. This interdependent relationship plays an important role in terms of supply risk and long term partnership. The DEA model is an effective approach for vendor evaluation but it cannot be used to evaluate the supply risk and partnership during the selection process. This important issue is often overlooked in the evaluation of vendors, especially when they are contracted by the government for longer terms and it can cause shortages and waste of vaccines.

In the nonlinear MCDA approach, a decision-maker could simultaneously consider a pool of suppliers from the evaluation process and also choose a set of suppliers to address supply risks and partnership issues. The basic notation of this process is defined as:

$$
\begin{aligned}
& N=\left\{v^{1}, \ldots, v^{n}\right\} \text { is the set of suppliers } \\
& P=\left\{p^{1}, \ldots, p^{m}\right\} \text { is the set of medical items } \\
& v^{i},(i=1, \ldots, n) \text { is supplier } i
\end{aligned}
$$


$p^{j}, \quad(j=1, \ldots, m)$ is medical item $j$

$I\left(v^{i}\right)$ is the number of medical items provided by supplier $v^{i}$ in the selection pool

$Q=\{1, \ldots, q\}$ is the set of interdependent criteria

$c_{k}^{i}$ is the effect of supplier $i$ on criterion $k$

$S_{k}$ is a set of suppliers that if selected together have some positive or negative effect on criterion $k$

$\gamma\left(S_{k}\right)$ is the amount of effect (positive or negative) of an interacting set $S_{k}$ on criterion $k$

$w_{k}$ is the weight associated with criterion $k$

$\phi(S)$ is the total payoff benefit of a subset of suppliers $S \subseteq N$

$D$ is the number of suppliers selected

$x_{i j}$ is equal to 1 if an supplier $v^{i}$ is selected for item $j$ and 0 otherwise

$$
y_{i}=\frac{\sum_{j=1}^{m} x_{i j}}{I\left(v^{i}\right)} \text { is }
$$
selected as a bundle of items and 0 otherwise.

In general, the interdependency relationship can be measured by a number of criteria: economies of scale, resource and risk sharing, and ownership or partnership. With regard to the interdependent relationship, there is a weight to each criterion, and the model is represented by a nonlinear programming function as follows:

$$
\begin{gathered}
\operatorname{Max} \sum_{\substack{i \in N \\
j \in P}} x_{i j}\left[\sum_{k \in Q} w_{k} c_{k}^{i}\right] \\
+\sum_{k \in Q} \sum_{s_{k} \subseteq N}\left(w_{k}\left[\gamma\left(S_{k}\right)\right]\left[\sum_{i \in s_{k}} c_{k}^{i}\right]\right) \prod_{\text {s.t. }} x_{i j} \\
\sum_{\substack{i \in S_{k} \\
y_{i} \leq D}} \\
x_{i j}, y_{i} \in\{0,1\}, i=1, \ldots, n, j=1, \ldots, m
\end{gathered}
$$

This function can be solved by a spreadsheet solver such as Frontline Premium Solver and provide the selection results for vendors in the next step of cost optimization. In the case of children's immunization problems, the schedule of combined vaccines will be included in the interdependent criteria in the decision model. The transportation cost optimization model is based on the fixed-charge transportation problem, which arises frequently in the application areas of scheduling and cost control. In a medical supply system, a variety of sources including international suppliers, local manufacturers, and wholesalers are all capable of sending medical supplies to a primary distributor. The primary distributor has to develop a transportation strategy for cost control.

The next step in the process of solving this issue is to model it as a fixed-charge transportation problem. The fixed charge problem determines the amount of shipments made from a given set of suppliers to a single destination, such that the total demand is satisfied at a minimum cost.. A fixed charge and cost proportional to the quantity shipped occurs when a supplier is employed. The fixed charge problem can be mathematically formulated in terms of an integer programming problem as follows:

$$
\operatorname{Min} T C=\sum_{i=1}^{M}\left(f_{i} d_{i}+F_{i} z_{i}\right)
$$

s.t.

$$
\sum_{i=1}^{M} d_{i}=D
$$

$$
\begin{gathered}
0 \leq d_{i} \leq b_{i} z_{i} \\
z_{i} \in\{0,1\} \text { and } i=1, \ldots, M
\end{gathered}
$$

Where $\mathrm{D}$ is the demand magnitude, $\mathrm{M}$ is the number of suppliers, $F_{i}$ is the fixed management cost incurred when using supplier $i, b_{i}$ is the capacity of supplier $i, f_{i}$ is the elective unit variable cost of supplier $i$, and $z_{i}$ is an integer variable taking the value of 1 when supplier $i$ is used, and 0 otherwise. The solution to the problem is a vector $d=\left(d_{1} . . d_{2} . . d_{M}\right)$ of nonnegative integers (also called the transportation profile) for which $d_{i}$ is the amount allocated to supplier $i$.

This linear integer programming model can be solved using a standard spreadsheet solver and reported to the decision maker in a numeric or graphic fashion.

\section{CONCLUSION}

While the analytical methods in this study are ready to be implemented, the collection of data from different sources may be limited. Different governmental agencies have their own lists of vendors and specific evaluation criteria/procedures under the Federal Acquisition Regulation System. In the case of childhood immunization, the list of vendors of vaccines and their cost profiles might not be frequently updated.

This study departs entirely from current acquisition practices and brings significant innovation to the current acquisition model. Its main advantages and innovations are: 1) automatic data collecting from different sources and forecasting of demands; 2) a new two-step decision model with the evaluation procedure of suppliers on quality management criteria, via a data envelopment analysis (DEA) approach, and the selection procedure of suppliers on supplier interdependent criteria, via a (MCDA) approach; 3) multiple issues can be addressed simultaneously in the model; 4) an integrated spreadsheet based software system that includes the cost of distribution and transportation and is designed to be easily to implemented with current medical management systems in public and private sectors. The proposed system also addresses the challenge of implementing the new government recommended immunization requirements in a cost effective manner. 


\section{ACKNOWLEDGMENT}

This research was supported in part by Texas A\&M International University Research Grant (2013-2015), Sanchez School of Business Summer Research Grant (2014).

\section{REFERENCES}

[1] Chamberlain, A.T., Wells, K., Seib, K., Kudis, A., Hannan, C., Orenstein, W.A., Whitney, E.A.S., Hinman, A.R., Buehler, J.W., Omer, S.B., and Berkelman, Lessons Learned From the 2007 to 2009 Haemophilus Iinfluenzae Type B Vaccine Shortage: Implications for Future Vaccine Shortages and Public Health Preparedness, Journal of Public Health Management and Practice, 18(3), pp. 9-16, 2012.

[2] Hinman, A.R., Orenstein, W.A., Santoli, J.M., Rodewald, L.E., and Cochi, S.L.: 'VACCINE SHORTAGES: History, Impact, and Prospects for the Future, Annual Review of Public Health, 27(1), pp. 235-259, 2006.

[3] Setia, S., Mainzer, H., Washington, M.L., Coil, G., Snyder, R., and Weniger, Frequency and causes of vaccine wastage, Vaccine, 20(7-8), pp. 1148-1156, 2002.

[4] Levinson, D., Preventing Health Care Fraud: New Tools and Approaches to Combat Old Challenges, Committee on Finance, 2011.

[5] World Health Organization, World Health Statistics, 2011.

[6] Fagnan, L.J., Shipman, S.A., Gaudino, J.A., Mahler, J., Sussman, A.L., and Holub, J.,To Give or Not to Give: Approaches to Early Childhood Immunization Delivery in Oregon Rural Primary Care Practices, The Journal of Rural Health, 27(4), pp. 385-393, 2011.

[7] Robison, S.G., Groom, H., and Young, C.,Frequency of Alternative Immunization Schedule Use in a Metropolitan Area, Pediatrics, 130, (1), pp. 32-38, 2012

[8] Safi, H., Wheeler, J.G., Reeve, G.R., Ochoa, E., Romero, J.R., Hopkins, R., Ryan, K.W., and Jacobs, R.F., Vaccine Policy and Arkansas Childhood Immunization Exemptions: A Multi-Year Review, American Journal of Preventive Medicine, 42(6), pp. 602-605, 2012.

[9] Coleman, M.S., Sangrujee, N., Fangjun, Z., and Susan, C.,Factors Affecting U.S. Manufacturers' Decisions To Produce Vaccines', Health Affairs, 24(3), pp. 635-642, 2005.

[10] Orenstein, W.,Protecting our Kids: What is Causing the Current Shortage in Childhood Vaccines?2002.

[11] Rodewald, L.E., Orenstein, W.A., Mason, D.D., and Cochi, S.L., Vaccine Supply Problems: A Perspective of the Centers for Disease Control and Prevention, Clinical Infectious Diseases, 42(Supplement 3), pp. S104-S110, 2006.

[12] Freed, G., and Cowen, A., State-Level Perspectives on Vaccine Purchase Financing, 2002.

[13] Shen, A.K., Rodewald, L.E., and Birkhead, G.S., Perspective of Vaccine Manufacturers on Financing Pediatric and Adolescent Vaccines in the United States, Pediatrics, 124(Supplement 5), pp. 540-S547, 2009.

[14] Russo, J.E., Meloy, M.G., and Wilks, T.J., Predecisional Distortion of Information by Auditors and Salespersons, Management Science, 46(1), pp. 13-17, 2000.

[15] Peckenpaugh, J.,New Rules Should Make Competition Routine in Government, Says OMB, 2003.

[16] Shehane, R.F., A framework for Knowledge-aware Service Contract Quality Management Decision Support Systems, Nova Southeastern University, 2006.

[17] Pitman, G.A., Motwani, J.G., and Schliker, D., Total Quality Mmanagement in the American Defence Industry - A Case Study, The International Journal of Quality \& Reliability Management, 11(9), pp. 101-101, 1994.

[18] Goh, M., and Tay, G.-H., Implementing a quality maintenance system in a military organization, The International Journal of Quality \& Reliability Management, 12(4), pp. 26-26, 1995.

[19] NASA Office of Inspector General, Review of Performance-Based Service Contract Quality Assurance Surveillance Plans, 2002.

[20] Bull, A., Specifying Quality in Health Care, Journal of Management in Medicine, 8 (2), pp. 5-8, 1994
[21] We, D., The New Economics for Industry, Government, Education, The MIT Press (2nd Edn.), 1994. 